\title{
ANALYSIS OF AIRPORTS USING CLUSTERING METHODS: CASE STUDY IN TURKEY
}

\section{DOI: 10.17261/Pressacademia.2018.963}

JMML- V.5-ISS.3-2018(4)-p.194-205

\section{Selin Yalcin ${ }^{1}$, Ertugrul Ayyildiz ${ }^{2}$}

${ }^{1}$ Beykent University, Istanbul, Turkey. selinyalcin@beykent.edu.tr, ORCID: 0000-0002-9926-2099

${ }^{2} Y_{\text {Ild }}$ Iz Technical University, Istanbul, Turkey. eayildiz@yildiz.edu.tr, ORCID: 0000-0002-6358-7860

To cite this document

Yalcin, S., Ayyildiz, E. (2018). Analysis of airports using clustering methods: case study in Turkey. Journal of Management, Marketing and Logistics (JMML), V.5(3), p.194-205.

Permemant link to this document: http://doi.org/10.17261/Pressacademia.2018.963

Copyright: Published by PressAcademia and limited licenced re-use rights only.

\begin{abstract}
Purpose- Airports in Turkey can be grouped using by various methods. One of these methods is clustering. In this study, 55 airports operating in Turkey, were analyzed by clustering methods.

Methodology- The airports are clustered according to similar features by the K-means method. The number of clusters was determined by using the elbow method. The clusters were verified by Ward's method. While clustering was being carried out, basic features such as passengers using airports, cargo carried by airports, and number of flights were used.

Findings- In this study, it has been seen that the airports have been divided into six clusters, two of which have just one element. It is also understood that five major airports(istanbul Ataturk, İstanbul Sabiha Gokcen, Ankara Esenboga, Izmir Adnan Menderes, Antalya) are quite different from other airports.

Conclusion- As a result, in this study, airports were clustered and similar airports were identified and a resource was prepared to assist managers in thinking that the solutions to common problems would be effective at similar airports.
\end{abstract}

Keywords: Airport, clustering, K-means, Elbow, Ward's.

JEL Classification: C380, C400, R40

\section{HAVALIMANLARININ KÜMELEME YÖNTEMLERIYLE INCELENMESI: TÜRKIYE ÖRNEĞi}

\section{ÖZET}

Amaç: Türkiye'deki havaalanları çeşitli yöntemlerle gruplandırılabilir. Bu yöntemlerden biri de kümelemedir. Bu çalışmada Türkiye'de faaliyet gösteren 55 havalimanı kümeleme metodu ile analiz edilmiştir.

Yöntem: Bu çalışma kapsamında havalimanları K-Ortalamalar yöntemiyle benzer özelliklerine göre kümelenmiştir. Küme sayısı, dirsek yöntemi (elbow method) ile belirlenmiştir. Oluşturulan kümeler Ward's yöntemi ile doğrulanmıştır. Kümeler oluşturulurken, havalimanlarını kullanan yolcu, havalimanlarından taşınan yük, uçuş sayısı gibi temel özellikler kullanıımıştır.

Bulgular: Bu çalışmada, havalimanlarının olan altı kümeye ayrıldığı görülmüştür. Bu kümelerin iki tanesinin yalnızca bir elemanı vardır. Ayrıca beş büyük havalimanının (İstanbul Atatürk, İstanbul Sabiha Gökçen, Ankara Esenboğa, İzmir Adnan Menderes, Antalya) diğer havalimanlarından oldukça farklı olduğu anlaşılmıştır.

Sonuç: Havalimanları kümelenerek benzer havalimanları tespit edilmiş, ortak sorunlara getirilen çözümlerin benzer havalimanlarında etkin olacağı düşünülerek yöneticilere yardımcı olacak bir kaynak hazırlanmıştır.

Anahtar Kelimeler : Havalimanı, Kümeleme, K-ortalamalar, Dirsek, Ward's.

JEL Classification: C380, C400, R40 


\section{GíRiş}

Günümüzde ekonominin hızla büyümesi ile birlikte havaalanlarının önemi giderek artmaktadır. İnsanların hayatlarında da zaman ve hız kavramı oldukça önemli bir hale gelmiştir. Aynı zamanda Türkiye'de yüksek hızıı tren alt yapısının zayıf olması ve bazı yol bağlantılarının yetersiz kalmasına bağlı olarak hava yolu taşımacılığının önemi son on yılda giderek arttırmıştır. Hava yolu taşımacılığı, uzun mesafeli şehirlerarası yolcu taşımacılığında, en iyi seçeneklerden biri olduğunu kanıtlamıştır (Tanyaş ve Düzgün, 2015). Bu sebeple, yolcuların ulaşım aracı olarak havalimanlarını tercih etmeleri kaçınılmaz olmuştur. Ayrıca, havacılık sektörü ülkelerin ekonomisi açısından oldukça stratejik bir öneme sahiptir. Gayri safi milli hasıla, büyümekte olan bir hava ulaşım sistemi ile doğrudan ilişkilidir. Havaalanları; ulusal ve uluslararası ekonomi göz önüne alındığında, insan ve mal taşımasında kilit öneme sahip ulusal kaynaklardır (Alıcı, 2017). Ekonominin büyümesine bağlı olarak artan talebin karşılanabilmesi için havalimanlarının sayısının arttırılması, var olan havalimanlarının daha etkin ve verimli çalışmasının sağlanması şart olmuştur. Rekabetin artmasıyla birlikte hava yollarında bulunan işletmeler ayakta kalabilmeleri için farklı stratejiler geliştirmek zorunda kalmışlardır. Düşük fiyatlı biletlerin satışa sunulması, işletmenin istediği rotalara uçuş yapabilmesi olanağının sağlanması gibi stratejiler geliştirilmeye başlanmıştır. Aynı zamanda ihracat edilen ürünler içinde havayollarının kullanımı oldukça önemlidir. Havalimanları, illerin ve ilçelerin gelişmesini de önemli ölçüde desteklemektedir. Havalimanlarına sadece ulaşım amacıyla bakılmamalıdır. Havalimanları artık ülkelerin dış dünyaya açılan bir kapısı olarak görülmektedir. Farklı coğrafyaları yakınlaştırarak turizm, ticaret ve farklı kültürlerin kaynaşmasına sebep olmuştur. Ülkeye gelen turistlerin ilk gördüğü yer ülkenin havalimanları olmaktadır. Ülkenin tanıtımı açısından havalimanlarının ne kadar önemli olduğu görülmektedir.

Değişen hedefler çerçevesinde, daha ileriye ve iyiye gitmek, diğer havaalanları ile rekabet edebilmek, havaalanlarının işletilmesinde hem kendi iç performanslarının değerlendirilmesi hem de diğer havaalanları ile performansların karşılaştırılarak belli göstergeler doğrultusunda hareket edilmesi gerekmektedir (Gökdalay ve Evren, 2009). 2008-2017 yılları arasında Türkiye geneli havalimanları yolcu, uçak ve yük trafiği incelendiğinde, 2016 yılı hariç artışın düzenli olarak devam ettiği görülmektedir. Devlet Hava Meydanları İşletmesi'nin (DHMi) 2018-2020 yılları arasında uçak, yolcu ve yük trafiği sayısı için yaptıkları tahminler bu artışın devam edeceği yönündedir (URL-1). Aynı zamanda, Türkiye hava ulaşımında stratejik bir konumda yer almaktadır. Ülkemiz, 1,5 milyar insanın yaşadığı, 35 milyar ABD doları GSMH ve 7 milyar ABD doları ticaret hacmine sahip ülkelere sadece 4 saat uçuş mesafesi uzaklı̆ındadır (URL -2). Bu sebeple, bu çalışmada konu olarak ülkeler için büyük bir öneme sahip olan havalimanları ele alınmıştır. Havalimanları ve veri madenciliğinin birlikte çalışıldığı sınırlı sayıda çalışma olduğu dikkate alınarak, Türkiye'deki 55 havalimanı, DHMi tarafından paylaşılan veriler doğrultusunda KOrtalamalar kümeleme yöntemi ve oluşturulan yöntemin doğrulanması için Ward's kümeleme yöntemi ile benzer özellikleri değerlendirilerek gruplandırılmıştır. Yapılan bu çalışmadan beklenen fayda, birbirlerine benzer veya tamamlayıcı şekilde çalışan işletmelerin birbirine yakın olmasını sağlayarak maliyetlerin en aza indirilmesi, benzer problemler üzerinde getirilebilecek çözümler açısından işbirliğin oluşmasını sağlanması şeklinde özetlenebilir.

Kümeleme yöntemi dünya ile birlikte ülkemizde de yapılan çalışmalarda çok farklı konularda kullanılmaktadır (Tanyaş, 2014). Geleneksel ticaret yöntemlerinin geride kaldığı bu dönemlerde taşıma faaliyetleri içerisinde yer alan havayolu taşımacııı̆ının önemi de giderek artmaktadır. Değişimin en fazla yaşandığı sektörlerden bir tanesi de havayolu taşımacılığıdır. İnsanlar hizmetlerini pahalıya alırken, niteliğinin de yüksek olmasına oldukça önem vermektedirler (URL-3). Bu sebeple, birbirlerine benzeyen havalimanlarının kümelenmesi ile yaşanacak herhangi bir sorunda kümeler içerisinde yer alan havalimanlarının birbirleri ile entegre olarak çalışmasını sağlamak, lojistik faaliyetleri açısından oldukça önemlidir. Bu çalışma ile birlikte, maliyetlerin azaltılması, önlemlerin alınması, havalimanlarının entegre olarak çalışmasının sağlanması amaçlanmaktadır. Birinci bölümün (giriş) ardından, ikinci bölümde havalimanları, K-Ortalamalar kümeleme yöntemi ve hiyerarşik kümeleme yöntemleri ile ilgili literatür taramasına yer verilmiştir. Üçüncü bölümde, çalışmada kullanılan KOrtalamalar kümeleme yöntemi ve karşılaştırma yapılabilmesi açısından kullanılan Ward's kümeleme yöntemi anlatılmıştır. Dördüncü bölümde, çalışmada kullanılan veriler ve bu verilerle elde edilen sonuçlara yer verilirken, çalışmanın son bölümlerinde uygulama sonucunda elde edilen bulgular hakkında değerlendirmeler yapılarak önerilerde bulunulmuştur.

\section{LITERATÜR TARAMASI}

Rekabetin artmasıyla havalimanlarının performanslarının değerlendirilmesi ilgili birçok çalışma yapılmıştır. Bu çalışmalar incelendiğinde, Ar (2012) tarafından 2007-2011 yılları arasında Devlet Hava Meydanları İşletmesi (DHMi) tarafından işletilen havalimanlarının etkinliklerinin ölçülmesi amacıyla; personel sayısı, pist/apron başına uçak kapasiteleri, alan başına yolcu, kapasiteleri, pist/apron başına gerçekleşen uçak trafiği, alan başına gerçekleşen yolcu trafiği, yük trafiği değişkenleri girdi ve çıktı olarak alınmış, çıkan sonuçlara göre etkinlik değerleri incelenmiştir. Ömürbek, Demirgubuz ve Tunca (2013) tarafından havalimanlarının performansları, uçuş trafiği, ticari uçuş trafiği, kargo trafiği, yolcu trafiği, satış gelirleri, giderler, hizmet verilen alan, yolcu kapasitesi, otopark kapasitesi, taşıt parkı, apron kapasitesi, uçak kapasitesi, bilgi işlem cihaz sayısı, kurtarma cihaz sayısı, personel sayısı gibi değişkenleri dikkate alarak Veri Zarflama Analizi yöntemiyle incelenmiştir. Türkiye'de faaliyet gösteren havalimanlarının 2013-2014 yılları arasındaki dönem bazında performanslarının incelenmesi personel sayısı, terminal alanı, yolcu sayısı, yük trafiği, toplam uçak trafiği değişkenleri girdi ve çıktı olarak alınarak Avcı ve 
Aktaş (2015) tarafından yapılmıştır. Tanyaş ve Düzgün (2015) DHMi tarafından paylaşılan verileri; uçak sayısı, koltuk kapasitesi, yurtiçi taşınan yük miktarı, yurt dışı taşınan yük miktarı, toplam taşınan yük miktarı, yurtiçi taşınan kargo miktarı, yurtdışı taşınan kargo miktarı, havayoluyla taşınan toplam kargo miktarı, yurtiçi hava trafiği, yurtdışı hava trafiği, toplam hava trafiği, yurtiçi toplam yolcu sayısı, yurtdışı toplam yolcu sayısı, toplam yolcu sayısı gibi kriterleri inceleyerek İstanbul'daki havalimanlarının artan talebi karşılamadığını yeni havalimanının yapılmasının gerekliliği sonucuna ulaşıımıştır. Avrupa'daki en büyük havalimanlarının Altın, Karaatlı ve Budak (2017) tarafından yolcu sayısı, terminal sayısı, otopark kapasitesi, pist sayısı, havalimanının şehir merkezine uzaklığı, çıkış kapı sayısı ve uçak stand sayısı kriterleri kullanılarak veri zarflama ve çok kriterli karar verme teknikleri ile performansları incelenmiştir.

Teknolojinin hızla artmasıyla büyük verilerin saklanabilmesi sağlanmıştır. Saklanan tüm bu verilerin anlamlandırılabilmesi için veri madenciliği kullanılmaktadır. Veri madenciliği ile verilerin ortak özellikleri yardımıyla gruplandırma yapmak mümkündür. Çalışmalar incelendiğinde, eğitim alanındaki veriler kullanılarak öğrencilerin üniversite giriş sınavı sonuçları ile başarıları arasındaki ilişki kümeleme analizi ve K-Ortalamalar yöntemi kullanılarak incelenmiştir (Erdoğan ve Timor, 2005). Türkiye'de 1997-2006 yıllarında meydana gelen trafik kazaları sonucunda her ilde meydana gelen ölüm ve yaralanma oranları hesaplanmıştır. Hesaplanan bu oranlar yardımı ile K-Ortalamalar ve bulanık K-Ortalamalar yöntemi kullanılarak kümeleme yapılmış, en yüksek ölüm ve yaralanma yaşanan iller tespit edilmiştir (Atalay ve Tortum, 2010). Sarıman tarafından (2011) yılında yapılan çalışmada K-Ortalamalar ve K-Medoids kümeleme algoritması ile ülkeler özelliklerine göre gruplandırma yapılmıştır. Fosil kökenli yakıtların çevreye verdiği zarardan dolayı yeni enerji kaynakları arayışları ortaya çıkmıştır. Biyogaz, diğer yakıtlara göre daha temiz ve yüksek enerji kaynağı olmasından dolayı hayvansal atıklarından biyogaz potansiyelini daha sağlıklı hesaplamak için tesisleri K-Ortalamalar kümeleme ile konumlarına göre ayırma yapılmıştır (Yürük ve Erdoğmuş, 2015). Ormanların sağlık kalitesi ve süreklilik göstergelerinden biri olağanüstü hasılat etası olduğu üzerinde durulmuştur. Orman Genel Müdürlüğünün verileri kullanılarak K-Ortalamalar yöntemi ile kümelere ayrılmıştır. Kümeler, her olağanüstü kesim grubu için ele alınmıştır (Çatal ve Carus, 2017). Türkiye'deki endüstriyel sektörlerin banka kredilerine göre kümelenmesi K-Ortalamalar yöntemi ve bulanık K-Ortalamalar yöntemi ile yapılmıştır (Dönme vd, 2017).

Literatür incelendiğinde havalimanları ve veri madenciliğinin birlikte çalışıldığı sınırlı sayıda çalışma bulunmaktadır (Çalış vd., 2018). Sarkis ve Talluri (2004) Havayolları ve hava taşıyıcılarının performans değerlendirmesi ve süreç iyileştirmesi hizmet faaliyetlerini yönetmek açısından önemlidir. Çok kriterli parametrik olmayan modeller kullanarak 5 tanesi büyük çaplı olmak üzere 44 havalimanının operasyonel verimliliği değerlendirilmiştir. Bu verimlilik puanları, kötü performans gösteren havaalanlarını iyileştirmek için kriterlerin belirlenmesinde, kümeleme yöntemi için kullanılmıştır. Suzuki (2007) yolcularının "iki adımlı" karar sürecini içeren havaalanı-havayolu seçimi için iç içe geçmiş bir model geliştirilmiş ve kararlar tahmin edilmiştir. Wang vd. (2009) havalimanlarının altyapı, bakım çizelgeleme gibi konularda önemli rol oynayan altyapı performanslarını baz alan ve kesin olmayan veriler kullanarak gri kümeleme metoduyla değerlendirmişlerdir. Fan vd. (2011) veri madenciliği ile havaalanı buz çözme faaliyetlerinin havaalanı çevresindeki alıcı suların kimyasal oksijen talebi ve çözülmüş oksijen üzerindeki etkilerini değerlendirmek için istatistiksel yöntemler kullanılmıştır. Karar ağacı modelleri havaalanı su yollarındaki kimyasal oksijen talebi ve çözülmüş oksijen düzeylerini tahmin etmek için kullanılmıştır Liou vd. (2011) havalimanının hizmet düzeyinin, yolcu açısından gelecekteki turizm ve iş faaliyetlerini teşvik etme veya cesaret kırma konusunda önemli bir etkiye sahip olabileceği vurgusu geleneksel istatistiksel analizin aksine, yeni bir yöntem ile anket uygulanarak model karar kuralları gerçekleştirilmiştir Wang ve Xu (2011) havalimanlarının kapasitelerinin ne derece etkin kullanıldığı konusunda belirleyici olan zemin tutma politikalarını değerlendirmek için kümeleme yöntemlerinden yararlanmışlardır. Günün farklı saatleri için farklı değerlerin kullanıldığı çalışma ele alınan havalimanında israfları azaltmıştır. Wang vd. (2011) yeni bir havalimanı kümeleme algoritması sundukları çalışmalarında havalimanlarını uçak trafiğine göre kümelemişlerdir. Wu vd. (2013) çoklu havalimanı sistemlerinde uçuş süresi ve sıklığının optimizasyon modelinde KOrtalamalar yönteminden yararlanmışlardır. Grabbe vd. (2014) benzer hava yolu trafiğine ve benzer hava koşullarına sahip havalimanlarını aktif gün ve saatlere odaklanarak kümelemişlerdir. Xia vd. (2014) havaalanı gürültü tahmini konulu çalışmalarında K-Ortalamalar yönteminden de yararlanmışlardır. Zhu vd. (2014) uçuş sıklığı ve zaman çizelgesi optimizasyonu konulu çalışmalarında K-Ortalamalar kümeleme yöntemine dayalı bir algoritma tasarlamışladır. Magalhaes vd. (2015) ana planlara dayalı geleneksel havaalanı geliştirme yaklaşımları artık yeterli olmamaktadır. Esneklik olası bir çözüm olarak ileri olmuştur. Literatürde konu ile ilgili yeterli çalışma olmaması sebebiyle, Kuzey Amerika, Avrupa ve Asya'daki 140 havalimanına kümeleme analizi uygulanmış ve bu havalimanlarının 20'si esnek olarak tanımlanmıştır. Meng ve Peng (2015) uçuşların gecikmeleri üzerine çalışarak K-Ortalamalar yöntemi ile bütünleşik yöntem kullanmışlar ve bunun yardımıyla rötar uyarıları için önemli bir referans sağlamışlardır. Mayer (2016) 114 havalimanı kargo özelliklerine göre hiyerarşik kümeleme yöntemi ile gruplandırmıştır. Cui vd. (2017) Çin'de 2010-2014 yılları arasında faaliyet gösteren 45 havalimanlarını K-Ortalamalar yöntemiyle kümeleyerek oluşturulan kümelerde yer alan havalimanlarının farklarını araştırmışlardır. Han vd. (2017) gecikmeden kaynaklanan uçuş problemlerinin çözümüne yönelik geliştirilen modelde 20 havalimanını hiyerarşik kümeleme yöntemiyle kümelemiştir. Yılmaz vd. (2017) Eskişehir'de potansiyel yolcu talebinin ölçülmesi, çapraz havayolu uçuşların gerçekleştirilebilmesi için ihtiyaç duyulan veriler karar ağaçları yardımıyla elde edilmiştir. Çalış vd. (2018) uçak seferlerindeki rötarları etkileyen faktörler veri madenciliği yöntemlerinden biri olan karar ağaçları yardımıyla analiz edilmiştir. Fuellhart ve O'Connor (2018) 2015 yılından itibaren havalimanı şehirleri ve 
bölgelerindeki faaliyetleri incelemişlerdir. Hiyerarşik kümelenme yöntemi kullanılarak, 53 havalimanı bölgesindeki 131 havalimanını, rekabet yönleri, güzergâhlar gibi değişkenler kullanılarak analiz etmişlerdir. Sonuç olarak incelenen havalimanlarının altı ana gruba ayrılabileceğini göstermişlerdir.

Yapılan bu çalışmada literatürdeki çalışmalardan farklı olarak, Türkiye'de yer alan havalimanlarına odaklanılmış ve bu havalimanları K-Ortalamalar yöntemi kümelendirilmiştir. Daha sonra Ward's yöntemi ile de oluşturulan kümelerin doğruluğu gösterilmiştir. Böylece Türkiye'de havacılık sektöründe yer alan yöneticilere yardımcı bir kaynak hazırlanması amaçlanmıştır.

\section{YÖNTEM}

\subsection{Veri Madenciliği}

Teknolojinin hızla ilerlemesiyle büyük miktardaki verilerin işlenmesi, saklı kalmış bilgilerin açığa çıkmasını sağlayan en önemli yöntemlerden biri veri madenciliğidir. Veri madenciliği, çok büyük miktardaki verilerin depolandığı veri tabanlarından, hedeflerimize ulaşabilmeyi sağlayacak anlamlı verilerin bulunması ve verilerin hedeflerimiz doğrultusunda gelecek hakkında tahmin yapmamamızı sağlayarak kullanılmaktadır. Karar verme alanında kullanılan en sık uygulamalardan biri de veri madenciliğidir. Örneğin; pazarlama, bankacılık, sağık, bilim ve mühendislik gibi birçok alanda uygulamaları mevcuttur (Savaş vd., 2012). Veri madenciliğinde kullanılan modeller, tahmin edici ve tanımlayıcı olmak üzere iki gruba ayrılmaktadır. Tahmin edici modellerde, sonuçları bilinen veriler doğrultusunda bir modelin geliştirilmesi, geliştirilen modele sonucu bilinmeyen veri setlerinin aktarılması ile sonuç değerlerinin tahmin edilmesi gerçekleştirilir. Tanımlayıcı modeller, var olan modellerde örüntülerin tanımlanmasıdır. Veri madenciliği modelleri sınıflama, kümeleme ve birliktelik kuralları olmak üzere üç ana gruptan oluşmaktadır (Özekes, 2003). Sınıflandırma, belli veri setlerinin hangi sınıf veya gruba dâhil olacağının belirlenmesidir. Kümeleme, veri setlerinin aralarındaki benzerliklere göre bir araya getirilerek küme oluşturulmasıdır. Birliktelik kuralları ise, veri setindeki potansiyel ilişkilerin ortaya çıkması olarak tanımlanmaktadır (Taşdelen, 2014). Bu çalışmada kullanılan veri madenciliği bir kümeleme uygulamasıdır.

Kümeleme, veri setlerinin aralarındaki benzerliklere göre bir araya getirilerek küme oluşturulmasıdır. Küme içerisinde üst düzey homojenlik, kümeler arasında ise üst düzey heterojenlik bulunmaktadır (Taşdelen, 2014). Kümeleme için kullanılan yöntemler, birimler arasındaki uzaklıklara dayanan benzerlik veya benzemezlik matrisine göre işlem yapmaktadırlar. Bu nedenle, farklı kümelenme yöntemleri farklı uzaklık ölçülerine göre farklı sonuçlar verebilmektedir. Ayırmaya dayanan kümelenme yöntemleri her veri setinin her bir birimini bir ve yalnızca bir kümeye ayırmaktadır. Böylelikle aşamalı ya da aşamalı olmayan kümelenme yöntemleri her bir birim için kesin karar almakta ve bir kümeye atamaktadır. Sonuçları itibariyle yaklaşık aynı sonuçları veren kümelenme yöntemlerinde bazı birimlerin farklı kümelerde yer aldığı gözlenebilmektedir (Murat ve Şekerler, 2009). Kümelemede kullanılan yöntemler, hiyerarşik ve hiyerarşik olmayan yöntemler olmak üzere ikiye ayrılmaktadır. Hiyerarşik yöntemlerde küme sayısı önceden bilinmemektedir. Başlangıç olarak her birinde bir birim veya değişken olan tek küme ile başlanmaktadır. Daha sonra benzer kümeler birleştirilerek ve çeşitli yöntemler kullanılarak kümeleme işlemine devam edilmektedir. Hiyerarşik olmayan yöntemlerde ise, başlangıç olarak küme sayısı yaklaşık olarak bilinmektedir. Her bir birim veya değişken en yakın olan kümeye dâhil edilmektedir. Bu sayede, $n$ adet veri nesnesinin k sayıda kümeye ayrılması sağlanmaktadır (Çakır vd., 2016). Hiyerarşik yöntem ve hiyerarşik olmayan yöntemler ardışık olarak kullanılabilmektedir.

\subsubsection{K-Ortalamalar Kümeleme Yöntemi}

Bu çalışmada, kümeleme yöntemlerinden biri olan K-Ortalamalar yöntemi kullanılmıştır. Bunun nedeni K-Ortalamalar yönteminin az sayıda küme oluşturulacak olan durumlarda hiyerarşik kümelemeye nazaran oldukça hızlı sonuç vermesi ve yöntemin, en çok bilinen kümeleme yöntemlerinden biri olmasıdır. K-Ortalamalar yöntemi, hiyerarşik olmayan bir yapıya sahiptir. Yöntem, 50 yıldan fazladır en çok kullanılan kümeleme yöntemlerinden biri olmuştur. Nesne sınıflandırma, görüntü bölümleme, makine öğrenmesi, veri madenciliği gibi uygulamaların dışında, iktisat, pazarlama, müşteri yönetimi, mühendislik araştırmaları gibi birçok alanda çok sıkıkla kullanılan yöntemlerin başında bulunmaktadır (Pekin vd., 2017).

$\mathrm{K}$-Ortalamalar yöntemi, bir $\mathrm{X}$ veri setine $\mathrm{n}$ adet veri nesnesinden $\mathrm{k}$ adet kümeye ayırma özelliğine sahiptir. Sınıflandırmada $\mathrm{k}$ adet kümenin merkezleri bulunmaktadır (Pekin vd., 2017). Özellik vektörleri kendine en yakın olan merkezlerde kümelenmektedir. İlk olarak k adet nesne seçmektedir. Bu nesnelerin her biri, bir kümenin merkezini veya orta noktasını temsil etmektedir. Geriye kalan nesnelerden her biri kendisine en yakın olan küme merkezine göre kümelere dağılmaktadır. Ardından her küme için ortalama hesaplanmaktadır. Hesaplanan bu değer o kümenin yeni merkezini oluşturmaktadır. Bu işlem tüm veri nesnelerin kümelere yerleşmesi tamamlanıncaya kadar (kümesi belli olmayan nesne kalmayıncaya kadar) devam etmektedir (Murat ve Şekerler, 2009). K-ortalamalar yönteminde nesneler kümelere ayrılırken denklem 1 ile gösterilen öklid uzaklığı formülü dikkate alınarak kümeleme yapılır. 
$d\left(X_{i}, X_{j}\right)=\sqrt{\sum_{p=1}^{m}\left(X_{i}^{p}-X_{j}^{p}\right)^{2}}$

(1)

Denklem 1'de $X_{1}, X_{2}, \ldots ., X_{n}$ nesneleri, $\mathrm{m}$ özellik sayısını, $X_{i}^{p}$ ise i nesnesinin $\mathrm{p}$ özelliğine ait değerini ifade etmektedir. KOrtalamalar yönteminin adımları aşağıda gösterilmiştir (Demiralay ve Çamurcu, 2005).

\section{K-Ortalamalar Yönteminin Adımları:}

1. Küme merkezlerini belirlemek için $n$ adet nesne arasından rastgele $k$ adet nesne seçilir. Bu nesneler küme merkezi olur.

2. Her nesnenin seçilen merkez noktalara olan uzaklığı Denklem 1'e göre hesaplanır. Elde edilen sonuçlara göre her nesne $k$ adet kümeden kendisine en yakın olan kümeye atanır.

3. Kümelerin yeni merkez noktaları o kümedeki tüm nesnelerin ortalama değeri olarak güncellenir.

4. Küme merkezleri sabit kalıncaya kadar adım 2 ve 3 tekrarlanır.

\subsubsection{Ward's Kümeleme Yöntemi}

Bu çalışmada, K-Ortalamalar yöntemine ek olarak hiyerarşik kümeleme yöntemlerinden en çok tercih edilen yöntemlerden biri olan Ward's yöntemi kullanılmıştır. Yöntem, en küçük varyans yöntemi olarak da bilinmektedir. Kümeler içi varyansı en küçük yapmayı hedeflemektedir (Çelik vd., 2005). Eş zamanlı olarak optimum kümeler elde etmeyi ve kümeleme yayılımının küçülmesini sağlamaktadır (Çelik ve Kahyaoğlu, 2007). Bir kümenin içerisinde bulunan gözlemin, aynı kümenin içerisinde yer alan diğer gözlemlerden ortalama uzaklığını dikkate almakta ve toplam sapma karelerinden yararlanmaktadır (Uysal vd., 2017). Yöntemde, küme sayılarının belirlenmesi ve kümelerin nasıl gruplandıkları genellikle dendrogram (ağaç grafiği) yardımı ile yapılır. Dendrogram, Ward's yöntemi ile elde edilen sonuçların grafiksel olarak gösterimidir. Dikey eksen küme oluşturulacak nesneleri, yatay eksen ise kümeler arasındaki uzaklıkları göstermektedir. Dendrogram, 0-25 birim arasında birbirine eşit birim olarak ölçeklendirilmektedir. Ölçek üzerinde kümelerin birleşme noktaları, hangi grupların nasıl oluştuğunu ve aralarındaki mesafeleri göstermektedir. Mesafe arttıkça, birbirine benzeyen nesneler kümeye dâhil olmaya başlarlar. En uzak mesafede olan nesneler birbirlerine en az benzeyen nesnelerdir (Tekin, 2015).

\section{UYGULAMA}

\subsection{Kullanılan Kriterler}

Literatür incelenerek ve uzmanlarla görüşülerek çalışmada kullanılan kriterler belirlenmiştir. Kriterler, havalimanlarını kullanan yolcu, havalimanlarından taşınan yük, uçuş sayısı olarak belirlenmiştir. Tablo 1'de DHMi tarafından paylaşılan 2017 Aralık sonu verileri kullanıımıştır. Verilerin analizinde "SPSS 25.0 for Windows" istatistiksel paket programı kullanılmıştır.

Tablo 1: DHMi 2017 Aralık Sonu Veriler (URL-1)

\begin{tabular}{|c|c|c|c|c|c|c|c|c|}
\hline \multirow{2}{*}{ Havalimanları } & \multicolumn{2}{|c|}{ Tüm Ucak Trafiği } & \multicolumn{2}{|c|}{ Yolcu Trafiŏi } & \multicolumn{2}{|c|}{ Ticari Ucak Trafiği } & \multicolumn{2}{|c|}{ Yük Trafiği } \\
\hline & íc Hat & Dis & İc Hat & Dis Hat & íc Hat & Dis Hat & İc Hat & Dis Hat \\
\hline İstanbul Atatürk & 142.886 & 317.89 & 19.450 .34 & 44.277 .101 & 134.735 & 314.713 & 203.058 & 1.899 .039 \\
\hline İstanbul Sabiha Gökcen & 139.311 & 80.345 & 21.056 .76 & 10.329 .074 & 134.572 & 76.353 & 137.171 & 193.698 \\
\hline Ankara Esenboğa & 99.682 & 18.138 & 13.853 .89 & 1.991 .979 & 91.509 & 15.237 & 95.829 & 33.620 \\
\hline İzmir Adnan Menderes & 72.343 & 17.578 & 10.469 .07 & 2.354 .622 & 66.095 & 16.758 & 87.200 & 48.481 \\
\hline Antalva & 51.928 & 107.41 & 7.459 .241 & 18.472 .418 & 49.233 & 105.935 & 67.336 & 228.808 \\
\hline Gazipasa Alanva & 4.140 & 2.244 & 475.775 & 347.463 & 3.482 & 2.180 & 4.624 & 4.047 \\
\hline Muğla Dalaman & 14.479 & 13.774 & 1.436 .326 & 2.274 .607 & 10.067 & 12.741 & 12.276 & 29.434 \\
\hline Muğla Milas-Bodrum & 20.522 & 7.997 & 2.573 .498 & 935.849 & 17.186 & 6.074 & 20.746 & 11.865 \\
\hline Adana & 38.585 & 6.351 & 4.963 .594 & 647.406 & 32.538 & 5.180 & 38.035 & 9.627 \\
\hline Trabzon & 26.187 & 2.911 & 3.952 .764 & 200.768 & 25.329 & 1.561 & 32.246 & 4.079 \\
\hline Erzurum & 9.838 & 197 & 1.366 .495 & 10.420 & 8.437 & 82 & 9.647 & 354 \\
\hline Gaziantep & 16.923 & 1.863 & 2.633 .359 & 289.062 & 15.689 & 1.793 & 22.107 & 4.744 \\
\hline Adıvaman & 2.005 & 17 & 256.207 & 1.990 & 1.838 & 16 & 1.882 & 40 \\
\hline Ağrı Ahmed-i Hani & 2.145 & 8 & 284.004 & 451 & 1.860 & 4 & 2.600 & 0 \\
\hline Amasva Merzifon & 1.554 & 82 & 215.351 & 8.905 & 1.447 & 71 & 1.631 & 200 \\
\hline Avdın Cıldır & 20.081 & 0 & & & & 0 & & 0 \\
\hline Balıkesir Koca Sevit & 22.829 & 120 & 431.088 & 9.177 & 3.176 & 119 & 2.961 & 177 \\
\hline Balıkesir Merkez & 134 & 0 & & & & 0 & & 0 \\
\hline Batman & 3.559 & 25 & 516.541 & 2.800 & 3.254 & 23 & 4.872 & 65 \\
\hline Bingöl & 1.480 & 19 & 163.220 & 1.270 & 1.223 & 18 & 1.524 & 15 \\
\hline Bursa Yenisehir & 7.715 & 382 & 227.228 & 24.051 & 1.722 & 260 & 2.070 & 647 \\
\hline Canakkale & 5.994 & 100 & 206.766 & 12.994 & 1.429 & 77 & 937 & 135 \\
\hline Canakkale Gökceada & 196 & 0 & 0 & 0 & 4 & 0 & 32 & 0 \\
\hline
\end{tabular}




\begin{tabular}{|c|c|c|c|c|c|c|c|c|}
\hline $\begin{array}{l}\text { Denizli Cardak } \\
\text { Divarbakır } \\
\text { Elazığ } \\
\text { Erzincan } \\
\text { Eskisehir Hasan Polatkan } \\
\text { Hakkari Yüksekova S.E. } \\
\text { Hatav } \\
\text { lğdır Sehit Bülent Avdın } \\
\text { Isparta Sülevman Demirel } \\
\text { Kahramanmaras } \\
\text { Kars Harakani } \\
\text { Kastamonu } \\
\text { Kavseri } \\
\text { Kocaeli Cengiz Topel } \\
\text { Konva } \\
\text { Malatva } \\
\text { Mardin } \\
\text { Mus } \\
\text { Kapadokva } \\
\text { Ordu-Giresun } \\
\text { Samsun Carsamba } \\
\text { Siirt } \\
\text { Sinop } \\
\text { Sivas Nuri Demirağ } \\
\text { Sanlıurfa Gap } \\
\text { Sırnak Serafettin Elci } \\
\text { Tekirdağ Corlu } \\
\text { Tokat } \\
\text { Usak } \\
\text { Van Ferit Melen } \\
\text { Zafer } \\
\text { Zonguldak Caycuma }\end{array}$ & \begin{tabular}{|l}
11.030 \\
12.763 \\
6.908 \\
3.376 \\
4.444 \\
1.251 \\
7.263 \\
1.778 \\
24.104 \\
2.578 \\
4.104 \\
891 \\
13.238 \\
1.456 \\
8.531 \\
7.084 \\
4.226 \\
2.992 \\
2.677 \\
8.119 \\
11.073 \\
386 \\
1.374 \\
4.077 \\
6.131 \\
2.452 \\
35.358 \\
442 \\
1.229 \\
13.799 \\
796 \\
238
\end{tabular} & $\begin{array}{l}618 \\
628 \\
227 \\
21 \\
668 \\
0 \\
2.303 \\
0 \\
606 \\
38 \\
6 \\
19 \\
2.101 \\
37 \\
878 \\
108 \\
37 \\
12 \\
24 \\
667 \\
523 \\
0 \\
106 \\
80 \\
168 \\
0 \\
565 \\
0 \\
8 \\
92 \\
188 \\
249\end{array}$ & $\begin{array}{l}592.167 \\
1.982 .048 \\
999.070 \\
439.611 \\
2.479 \\
154.795 \\
1.002 .715 \\
247.516 \\
86.401 \\
297.848 \\
572.891 \\
89.576 \\
1.886 .729 \\
46.445 \\
1.099 .942 \\
880.299 \\
677.734 \\
439.767 \\
127.158 \\
1.109 .268 \\
1.111 .627 \\
22.684 \\
152.230 \\
571.692 \\
814.025 \\
341.047 \\
102.567 \\
13.084 \\
0 \\
1.662 .576 \\
81.621 \\
0\end{array}$ & $\begin{array}{l}91.845 \\
72.999 \\
28.000 \\
1.175 \\
77.462 \\
0 \\
277.449 \\
0 \\
103.108 \\
2.615 \\
0 \\
1.754 \\
260.967 \\
2.730 \\
105.764 \\
7.168 \\
3.276 \\
1.528 \\
425 \\
83.857 \\
40.526 \\
0 \\
1.766 \\
6.535 \\
18.943 \\
0 \\
1.768 \\
0 \\
0 \\
2.353 \\
21.261 \\
24.904\end{array}$ & $\begin{array}{l}4.050 \\
12.455 \\
6.532 \\
2.924 \\
29 \\
1.189 \\
6.744 \\
1.582 \\
674 \\
2.157 \\
3.622 \\
759 \\
12.404 \\
302 \\
8.134 \\
5.574 \\
4.320 \\
2.801 \\
958 \\
7.106 \\
7.789 \\
300 \\
1.159 \\
3.698 \\
5.510 \\
2.144 \\
772 \\
164 \\
0 \\
10.334 \\
729 \\
0\end{array}$ & $\begin{array}{l}559 \\
621 \\
218 \\
17 \\
554 \\
0 \\
2.259 \\
0 \\
606 \\
17 \\
0 \\
19 \\
1.996 \\
19 \\
840 \\
61 \\
26 \\
12 \\
5 \\
663 \\
337 \\
0 \\
8 \\
77 \\
167 \\
0 \\
95 \\
0 \\
0 \\
20 \\
184 \\
234\end{array}$ & $\begin{array}{l}4.666 \\
14.253 \\
8.337 \\
3.613 \\
128 \\
1.438 \\
8.926 \\
2.605 \\
675 \\
2.516 \\
5.290 \\
612 \\
16.119 \\
421 \\
8.935 \\
6.975 \\
6.188 \\
3.756 \\
990 \\
8.496 \\
7.353 \\
181 \\
1.363 \\
4.846 \\
5.980 \\
3.020 \\
607 \\
88 \\
0 \\
13.297 \\
630 \\
66\end{array}$ & $\begin{array}{l}1.557 \\
971 \\
701 \\
28.54 \\
1.611 \\
0 \\
4.557 \\
0 \\
1.553 \\
61 \\
0 \\
43 \\
5.973 \\
57 \\
2.355 \\
157 \\
12 \\
21 \\
11 \\
1.560 \\
1.107 \\
0 \\
26 \\
142 \\
493 \\
0 \\
1.209 \\
0 \\
0 \\
62 \\
517 \\
504\end{array}$ \\
\hline
\end{tabular}

\subsection{K-Ortalamalar Yöntemi ile Havalimanlarının Kümelenmesi}

Kümeleme işlemi gerçekleştirilirken yapılan denemeler sonucunda, ele alınan 8 kriterin her birinde oldukça yüksek değerlere sahip olan en büyük 5 havalimanı ayrı tutulmuştur. Bunun nedeni, küme sayısı ne olursa olsun bu havalimanlarının her birinin ayrı kümede yer alarak küme merkezi olmasıdır. Bu da çalışmada daha az kullanılan havalimanlarının incelenmesinde zorluklar çıkarmaktadır. Bu 5 büyük havalimanın elemanları kendi başlarına ayrı bir küme şeklinde düşünülmüştür. Havalimanlarının çıkarılmasıyla elde kalan 50 havalimanı için kümeleme işlemi gerçekleştirilmiştir. K-Ortalamalar yönteminde, küme sayısı 2'den başlayarak 10'a kadar arttırılmış ve sonuçlar elde edilmiştir. Küme sayısı belirlenirken dirsek yöntemi uygulanmıştır.

Dirsek yöntemi, bir veri kümesinde uygun sayıda kümenin bulunmasına yardımcı olmak üzere tasarlanan kümeleme analizi içindeki tutarlılığın yorumlanması ve doğrulanması için bir yöntemdir. Daha doğru kümelenme yapılmasına yardımcı olmaz. Dirsek yöntemi kümeler için karesel hatanın hesaplanması yardımıyla gerçekleştirilmektedir. Yöntemde her bir küme sayısı için karesel hata hesaplanır ve yatay eksene küme sayısı, dikey eksene karesel hata gelecek şekilde grafiğe yerleştirilir. Karesel hatanın düşük olması kümeleme modelinin daha iyi olduğu anlamına gelmektedir. Daha sonra grafik incelenir. Grafikte karesel hatanın azalma hızının düştüğü nokta ideal küme sayısı olarak belirlenir. Aşağıda verilen Şekil 1'de çalışmada farklı küme sayıları için elde edilen karesel hatalar grafikte gösterilmiştir. Grafikten de görülebileceği üzere küme sayısı 6 olana kadar karesel hata hızla düşmektedir. 6'dan sonra ise yatay bir seyir izlemekte olan grafikten ideal küme sayısının 6 olduğu anlamı çıkarılabilir. 6'dan sonra artan küme sayısı, karesel hatayı çok fazla azaltmadığı gibi modelin yorumlanabilirliğini de düşürmektedir. 
Şekil 1. Dirsek Yöntemi

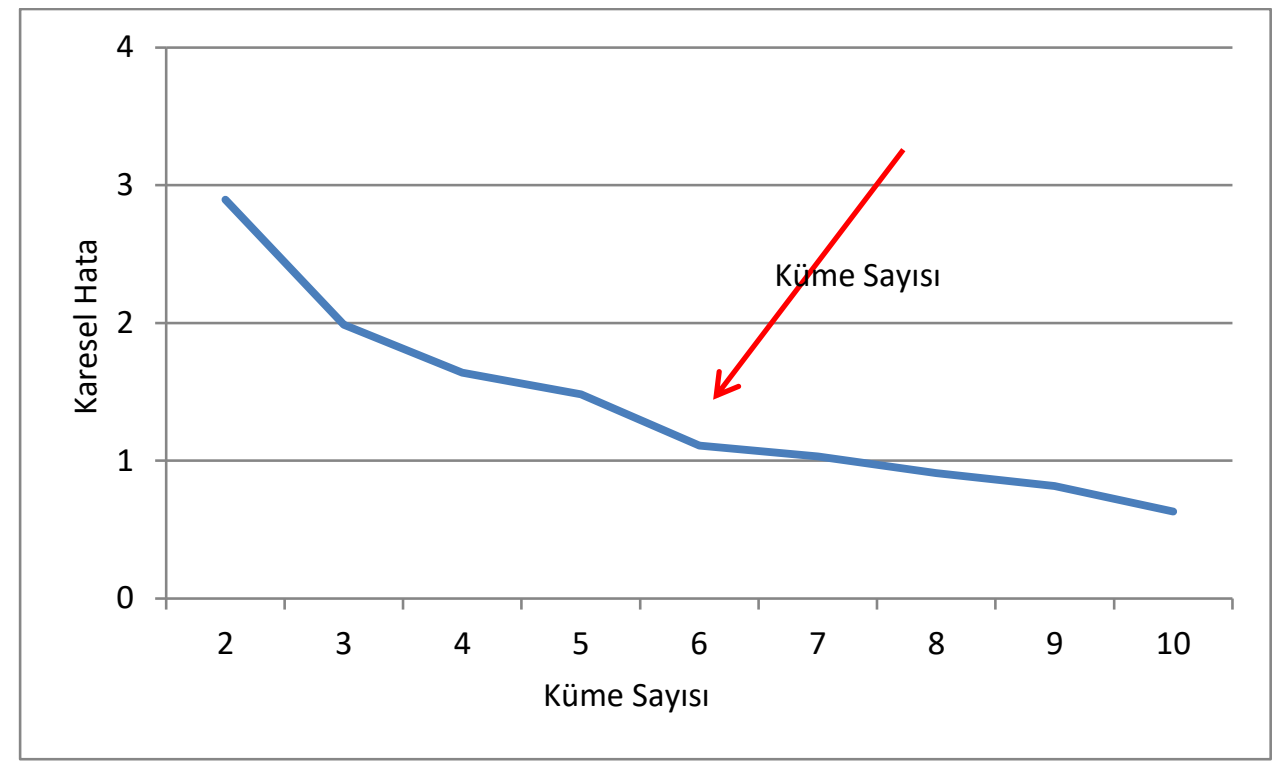

Dirsek yöntemi ile küme sayısının 6 olmasına karar verilmiştir. Küme sayısı belirlendikten sonra K-Ortalamalar kümeleme yöntemi ile elde edilen sonuçlara göre havalimanlarının hangi kümeler dâhil olduğu Tablo 2' de gösterilmiştir.

Tablo 2: K-Ortalamalar Yöntemi ile Elde Edilen Kümeleme Sonuçları

\begin{tabular}{|c|c|c|c|c|c|c|c|}
\hline \multicolumn{3}{|l|}{ Küme 1} & \multirow{2}{*}{\begin{tabular}{|l} 
Küme 2 \\
Erzurum
\end{tabular}} & \multirow{2}{*}{\begin{tabular}{|l} 
Küme 3 \\
Muğla \\
Dalaman
\end{tabular}} & \multirow{2}{*}{$\begin{array}{l}\text { Küme } 4 \\
\text { Adana }\end{array}$} & \multirow{2}{*}{$\begin{array}{l}\text { Küme } 5 \\
\text { Trabzon }\end{array}$} & \multirow{2}{*}{$\begin{array}{l}\text { Küme } 6 \\
\text { Aydın Çıldır }\end{array}$} \\
\hline Gazipaşa Alanya & Erzincan & Kapadokya & & & & & \\
\hline Adıyaman & Eskişehir H.P. & Siirt & Denizli Çardak & Muğla Milas & & & Balıkesir K.S. \\
\hline Ağrı Ahmed-i Hani & Hakkari Y.S.E. & Sinop & Elazığ & Gaziantep & & & Isparta S.D. \\
\hline Amasya Merzifon & Iğdır Ş.B.A. & Sivas N.D. & Hatay & Diyarbakır & & & $\begin{array}{l}\text { Tekirdağ } \\
\text { Çorlu }\end{array}$ \\
\hline Balıkesir Merkez & Kahramanmaraş & Şırnak Ş.E. & Konya & Kayseri & & & \\
\hline Batman & Kars Harakani & Tokat & Malatya & $\begin{array}{ll}\text { Van } & \text { Ferit } \\
\text { Melen } & \end{array}$ & & & \\
\hline Bingöl & Kastamonu & Uşak & Ordu-Giresun & & & & \\
\hline Bursa Yenişehir & Kocaeli C.T. & Zafer & $\begin{array}{l}\text { Samsun } \\
\text { Çarşamba }\end{array}$ & & & & \\
\hline Çanakkale & Mardin & Zonguldak & Şanlıurfa Gap & & & & \\
\hline Gökçeada & Muş & & & & & & \\
\hline
\end{tabular}

K-Ortalamalar yöntemi uygulanırken farklı başlangıç noktaları çalıştırılmış ve hatanın en aza indirgendiği nokta belirlenmiştir. Kullanılan verilerde aralıkların birbirinden farklı olması nedeniyle normalizasyon uygulanan yöntemde k=2,3,4,5,6,7,8,9,10 değerleri için denemeler yapılmıştır. İdeal küme sayısının 6 olduğu çalışmada, küme $1^{\prime}$ de 29, küme 2'de 9, küme 3'de 6, küme 4'de 1, küme 5'te 1 ve küme 6'da 4 havalimanı yer almıştır.

Tablo 2 incelendiğinde, birbirlerine benzerlik gösteren havalimanları K-Ortalamalar kümeleme yöntemi ile 6 kümede gruplandırılmıştır. Türkiye'nin en aktif 5 havalimanın (İstanbul Atatürk, İstanbul Sabiha Gökçen, Ankara Esenboğa, İzmir Adnan Menderes, Antalya) ayrı olarak değerlendirildiği bu çalışmada, sonuçlar incelendiğinde en kalabalık küme olarak küme 1 karşımıza çıkmaktadır. 29 havalimanın dâhil olduğu bu kümeye odaklanıldığı takdirde aktif olarak kullanılan fakat çok fazla rağbet görmeyen havalimanlarının yer aldığı görülmektedir. Çok yoğun uçuşların bulunmadığı bu havalimanlarının işletmelerinde de benzer problemlerle karşılaşılabileceği söylenebilir. Küme 2'de ise ortalama değerlere sahip 9 havalimanı yer almıştır. Küme 2'de yer alan havalimanlarının Elazığ dışında tamamının yer aldığı şehirler, büyükşehir belediyesine sahip şehirlerdir. Ortalama uçuş yoğunluğuna sahip havalimanlarının yer aldığı bu kümede turizmin çok gelişmediğini söylemek 
hata olmayacaktır. Küme 3'te ise görece yoğun 6 havalimanı yer almıştır. Küme 2 gibi büyükşehir belediyelerine sahip bu kümede Küme 2'ye göre turizmin gelişmiş olduğu şehirler yer almıştır. Küme 4 ve 5 ise Adana ve Trabzon havalimanlarının kendi başlarına küme merkezi olduğu kümelerdir. Bunun nedeni olarak bu 2 havalimanın ele alınan havalimanlarından en aktif olanları olması gösterilebilir. Son olarak Küme $6^{\prime}$ da ise aktif olarak işletilmeyen 4 havalimanı yer almıştır. Tüm kümelerin birbirlerinden ayrıırken farklı özelliklere sahip olması çalışmanın doğruluğunu kanıtlar niteliktedir.

Tablo 3: K-Ortalamalar Yöntemine Göre ANOVA Sonuçları

\begin{tabular}{|l|l|l|l|l|l|l|}
\hline \multirow{2}{*}{ Kriterler } & \multicolumn{2}{l|}{ Küme } & \multicolumn{2}{l|}{ Hata } & Anlamlılık \\
\cline { 2 - 6 } & Ort. Karesel Hata & df & Ort. Karesel Hata & df & & Düzeyi \\
\hline Uçak trafiği- İç hatlar &, 037 & 5 &, 000 & 44 & 109,451 &, 000 \\
Uçak trafiği- Dış hatlar &, 000 & 5 &, 000 & 44 & 7,170 &, 000 \\
Yolcu trafiği- İç hatlar &, 022 & 5 &, 000 & 44 & 149,671 &, 000 \\
Yolcu trafiği- Dış hatlar &, 000 & 5 &, 000 & 44 & 5,034 &, 001 \\
Ticari Uçak Trafiği- İç hatlar &, 022 & 5 &, 000 & 44 & 159,303 &, 000 \\
Ticari Uçak Trafiği- Dış hatlar &, 000 & 5 &, 000 & 44 & 6,402 &, 000 \\
Yük trafiği- İç hatlar &, 014 & 5 &, 000 & 44 & 128,051 &, 000 \\
Yük trafiği- Dış hatlar &, 000 & 5 &, 000 & 44 & 6,082 &, 000 \\
\hline
\end{tabular}

ANOVA sonuçları yardımıyla, kriterlerin kümeler itibariyle farklılık gösterip göstermediğinin incelenemebilmektedir. Beklenen, kriterlerin kümeler itibariyle farklı çıkmasıdır. Kümeleme analizi, bu farklılı̆ı kendi oluşturmakta ve kümeler arası farkı (uzaklığı) maksimum yapmaktadır. Tablo 3'de yer alan ANOVA tablosu sonuçlarına göre kullanılan kriterlerin kümelere göre farklııık göstermektedir. Bu da tüm kriterler için anlamlılık düzeyinin 0,005'ten küçük olması ile anlaşılmıştır.

\subsection{Ward's Yöntemi ile Havalimanlarının Kümelenmesi}

Hiyerarşik kümeleme yöntemlerinden olan Ward's yöntemi uygulanırken, K-Ortalamalar yönteminde yapıldığı gibi ele alınan 8 kriterin her birinde oldukça yüksek değerlere sahip olan en büyük 5 havalimanı ayrı tutularak kümeleme yöntemi uygulanmıştır. Verilerde aralıkların birbirinden farklı olması nedeniyle normalizasyon uygulanmıştır. Küme sayılarının belirlenmesi ve kümelerde yer alan havalimanlarının nasıl gruplandıkları Şekil 2'de gösterilen dendrogram (ağaç grafiği) ile yapılmıştır. 
Şekil 2: Ward's Yöntemi Kullanılarak Oluşturulan Ağaç Grafiği

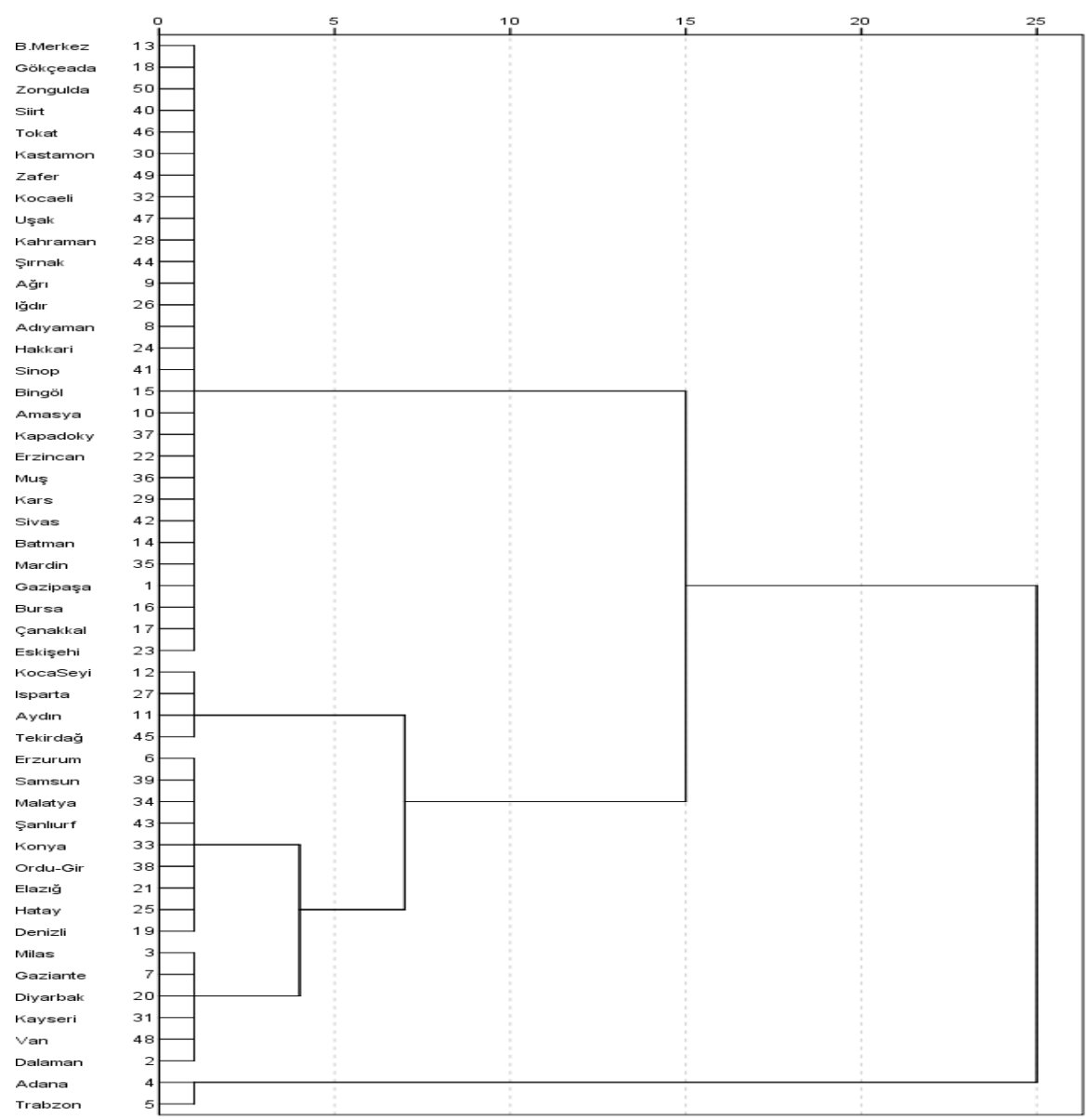

Şekil 2'ten görülebileceği üzere Ward's yönteminin sonuçlarına göre, küme 1'de 29, küme 2'de 4, küme 3'de 9, küme 4'de 6, küme 5 'te 2 havalimanı yer almıştır.

Illk birleşen havalimanları, Balıkesir Merkez, Çanakkale Gökçeada, Zonguldak Çaycuma, Siirt, Tokat, Kastamonu, Zafer, Kocaeli Cengiz Topel, Uşak, Kahramanmaraş, Şırnak Şerafettin Elçi, Ağrı Ahmed-i Hani, Iğdır Şehit Bülent Aydın, Adıyaman, Hakkâri Yüksekova, Sinop, Bingöl, Amasya Merzifon, Kapadokya, Erzincan, Muş, Kars Harakani, Sivas Nuri Demirağ, Batman, Mardin, Gazipaşa Alanya, Bursa Yenişehir, Çanakkale, Eskişehir Hasan Polatkan Küme 1'i oluşturmaktadır. İkinci birleşen havalimanları, Balıkesir Koca Seyit, Isparta, Aydın Çıldır, Tekirdağ Çorlu Küme 2'i oluşturmaktadır. Üçüncü birleşen havalimanları, Erzurum, Samsun Çarşamba, Malatya, Şanlıurfa Gap, Konya, Ordu- Giresun, Elazı̆̆, Hatay, Denizli Çardak Küme 3'ü oluşturmaktadır. Dördüncü birleşen havalimanları, Muğla Milas, Gaziantep, Diyarbakır, Kayseri, Van Ferit Melen, Muğla Dalaman havalimanları Küme 4'ü oluşturmaktadır. Beşinci birleşen havalimanları, Adana ve Trabzon Küme 5'i oluşturmaktadır. Elde edilen tüm kümeler Tablo 4'te gösterilmiştir.

Tablo 4: Ward's Yöntemi ile Elde Edilen Kümeleme Sonuçları

\begin{tabular}{|lll|l|l|l|l|}
\hline Küme $\mathbf{1}$ & & & Küme 2 & Küme 3 & Küme 4 & Küme 5 \\
\hline Gazipaşa Alanya & Erzincan & Kapadokya & Aydın Çıldır & Erzurum & Muğla Dalaman & Adana \\
Adıyaman & Eskişehir H.P. & Siirt & Balıkesir K.S. & Denizli Çardak & Muğla Milas & Trabzon \\
Ağrı Ahmed-i Hani & Hakkâri Y.S.E. & Sinop & Isparta S.D. & Elazı̆̆ & Gaziantep & \\
Amasya Merzifon & Iğdır Ş.B.A. & Sivas N.D. & Tekirdağ Çorlu & Hatay & Diyarbakır & \\
Balıkesir Merkez & Kahramanmaraş & Şırnak Ş.E. & & Konya & Kayseri &
\end{tabular}




\begin{tabular}{|lll|l|l|l|} 
Batman & Kars Harakani & Tokat & Malatya & Van Ferit Melen \\
Bingöl & Kastamonu & Uşak & Ordu-Giresun & \\
Bursa Yenişehir & Kocaeli C.T. & Zafer & Samsun Çarşamba & \\
Çanakkale & Mardin & Zonguldak & & Şanlıurfa Gap & \\
Gökçeada & Muş & & & \\
\hline
\end{tabular}

Hiyerarşik olmayan kümeleme yöntemlerinden biri olan K-Ortalamalar yönteminde elde edilen sonuçlar ile hiyerarşik kümeleme yöntemlerinden biri olan Ward's yönteminde elde edilen sonuçlar karşılaştıııldığında, elde edilen kümelerdeki havalimanlarının bire bir aynı olduğu sadece Ward's yönteminde, K-Ortalamalar yönteminde ayrı iki küme olarak ortaya çıkan Adana ve Trabzon havalimanlarının bir arada kümelediği gözlemlenmiştir. Bu farkın olmasının en temel nedeni olarak, Adana ve Trabzon havalimanlarının İstanbul, İzmir, Ankara ve Antalya'da bulunan havalimanlarına benzeyerek aykırı iki nokta olması gösterilebilir. Sonuç olarak, küme sayısı belirtilerek yapılan analiz ile küme sayısı belirtilmeden yapılan analiz tutarlı sonuçlar vermektedir.

\section{SONUÇ}

Ekonominin büyümesine bağı olarak artan talebin karşılanabilmesi için havalimanlarının sayısının arttıııması, var olan havalimanlarının daha etkin ve verimli çalışmasııın sağlanması şart olmuştur. ihracat ve ithalat işlemlerinde havayollarının kullanımı oldukça önemlidir. Havalimanları, illerin ve ilçelerin gelişmesini de önemli ölçüde desteklemektedir. Bu çalışmada, konu olarak ülkeler için büyük bir öneme sahip olan havalimanları ele alınmıştır. Havalimanları ve veri madenciliğinin birlikte çalışıldığı sınırlı sayıda çalışma olduğu dikkate alınarak, Türkiye'deki 55 havalimanı, DHMi tarafından paylaşılan veriler doğrultusunda hiyerarşik kümeleme yöntemlerinden olmayan K-Ortalamalar yöntemi ve hiyerarşik kümeleme yöntemlerinden olan Ward's yöntemi ile benzer özellikleri değerlendirilerek gruplandırılmıştır. K-Ortalamalar yönteminde küme sayısı dirsek yöntemi ile 6 olarak belirlenmiştir. Tablo 2 dikkate alındığında, oluşturulan 6 küme içerisinde yer alan havalimanlarının ele alınan kriterler ve veriler doğrultusunda benzerlik gösterdiği sonucu ortaya çıkmıştır. Ward's yöntemi küme sayısını 5 olarak vermiştir. Ayrık olarak nitelendirebileceğimiz Adana ve Trabzon havalimanlarını tek bir kümede gruplandırmıştır. Günümüzde bu denli öneme sahip olan havalimanları üzerinde daha fazla durulmalı ve çalışmalar yapılmalıdır. Kullanılan kriterlere ek kriterler eklenerek çalışma geliştirilebilir. Literatürde havalimanları ve veri madenciliği uygulamasının yetersiz olduğu görülmekte ve veri madenciliği yöntemlerinden olan kümeleme, sınıflandırma ve karar ağacı gibi uygulamalar yapılarak havalimanları incelenmelidir. Veri madenciliği, gizli kalmış bilgilerin açığa çıkmasına yardımcı olması yönüyle havalimanlarının performansını, müşteri memnuniyetini veya kapasitesini verimli kullanması açısından faydalı olacağı düşünülmektedir. Ayrıca sonuç olarak bu çalışmada havalimanları kümelenerek benzer havalimanları tespit edilmiş, ortak sorunlara getirilen çözümlerin benzer havalimanlarında etkin olacağı düşünülerek yöneticilere yardımcı olacak bir kaynak hazırlanmıştır.

\section{KAYNAKÇA}

Alıcı, A. (2017). Havalimanı gelir türleri ve havacılık dışı ticari gelirlerin önemi. Hukuk ve İktisat Araştırmaları Derneği, 9(2), ss. 1-16.

Altın, F. G., Karaatlı, M., Budak, İ. (2017). Avrupa'nın en büyük 20 havalimanın çok kriterli karar verme yöntemleri ve veri zarflama analizi ile değerlendirilmesi. Süleyman Demirel Üniversitesi İktisadi ve İdari Bilimler Fakültesi Dergisi, 22(4), ss.1049-1064.

Ar, í. M. (2012). Türkiye'deki havalimanlarının etkinliklerindeki değişimin incelenmesi: 2007- 2011 dönemi için Malmquist-Tfv endeksi uygulaması. Atatürk Üniversitesi İktisadi ve İdari Bilimler Dergisi, 26(3-4), ss.143-160.

Atalay, A., Tortum, A. (2010). Türkiye'deki illerin 1997-2006 yılları arası trafik kazalarına göre kümeleme analizi. Pamukkale Üniversitesi Mühendislik Bilimleri Dergisi, 16(3), ss. 335-343.

Avcı, T., Aktaş, M. (2015). Türkiye'de faaliyet gösteren havalimanlarının performanslarının değerlendirilmesi. Uluslararası Alanya İşletme Fakültesi Dergisi, 7(3), ss.67-77.

Cui, Q., Wei, Y.-M., Li, Y., Li, W.-X. (2017). Exploring the differences in the airport competitiveness formation mechanism: evidence from 45 Chinese airports during 2010-2014. Transportmetrica B, 5(3), ss. 330-346.

Çakır Zeytinoğlu, F., Çağlayan Akay, E., Karabıyık Yerden, N. (2016). İstanbul'daki alışveriş merkezleri üzerine bir araştırma: kümeleme analizi. Social Sciences Research Journal, 5(1), ss.111-128.

Çalış Boyacı, A., Durmaz, K. İ., Gencer, C. (2018). Uçak seferlerindeki rötarları etkileyen faktörlerin analizi. Uluslararası İktisadi ve İdari İncelemeler Dergisi,11(18), ss.179-190. 
Çatal, Y., Carus, S. (2017). Kümeleme analizi ile orman bölge müdürlüklerinin olağanüstü hasılat etasına göre sınıflandırılması. Türkiye Ormancılık Dergisi, 18(2), ss.119-124.

Çelik, H. C., Kakyaoğlu, M. (2007). İlköğretim öğretmen adaylarının teknolojiye yönelik tutumlarının kümeleme analizi. Türk Eğitim Bilimleri Dergisi, 5(4), 571-586.

Çelik, H.C., Satıcı, Ö., Çelik, M. Y. (2005). Sağlık Personellerinde kronik sigara içme alışkanlığı olanların tutumlarına ilişkin değişkenlerin kümeleme analizi (Cluster Analysis). Dicle Tıp Dergisi, 32(1), ss. 20-25.

Demiralay, M., Çamurcu, A. Y. (2005). Cure, agnes ve k-means algoritmalarındaki kümeleme yeteneklerinin karşılaştırılması. İstanbul Ticaret Üniversitesi Fen Bilimleri Dergisi, 4(8), 1-18.

Dönme, C. Ç., Hopali, E., Hamal , S. (2017). Endüstri sektörlerinin ekonofizik açıdan kümelenme analizi: Türkiye uygulaması. Elektronik Sosyal Bilimler Dergisi, 16(63), ss.1081-1091.

Erdoğan, Ş. Z., Timor, M. (2005). A data mining application in a student database. Journal of Aeronautics and Space Technologies, 2(2), ss.53-57.

Fan, H., Tarun, P. K., Shih, D. T., Kim, S. B., Chen, V. C., Rosenberger, J. M., Bergman, D. (2011). Data mining modeling on the environmental impact of airport deicing activities. Expert Systems with Applications, 38, ss.14899-14906.

Fuellhart, K., O'Connor, K. (2018). A supply-side categorization of airports across global multiple-airport cities and regions. GeoJournal, ss. $1-16$.

Grabbe, S., Sridhar, B., Mukherjee, A. (2014). Clustering days and hours with similar airport traffic and weather conditions. Journal of Aerospace Information Systems, 11(11), ss. 751-763.

Gökdalay, M. H., Evren, G. (2009). Havaalanlarının performans analizinde bulanık çok ölçütlü karar verme yaklaşımı. itüdergisi/d mühendislik, 8(6), ss. 157-168.

Han, X., Hou, Y., Zhang, H. (2017). Optimization model and algorithm of the flight delays. Liaoning Gongcheng Jishu Daxue Xuebao (Ziran Kexue Ban)/Journal of Liaoning Technical University (Natural Science Edition), 36(5), ss. 542-547

Liou, J. J., Tang , C.-H., Yeh, W.-C., Tsai, C.-Y. (2011). A decision rules approach for improvement of airport sevice quality. Expert Systems with Applications, 38, ss.13723-13730.

Magalhaes, L., Reis, V., Macario, R. (2015). Can flexibility make the difference to an airport's productivity? An assessment using cluster analysis. Journal of Air Transport Management, 47, ss. 90-101.

Mayer, R. (2016). Airport classification based on cargo characteristics. Journal of Transport Geography, 54, ss. 53-65.

Meng, H., Peng, Y. (2015). Two-stage extraction method for flight delay pattern. Harbin Gongye Daxue Xuebao/Journal of Harbin Institute of Technology, $47(10)$, ss. $70-75$.

Murat, Y. Ş., Şekerler, A. (2009). Trafik kaza verilerinin kümelenme analizi yöntemi ile modellenmesi. iMO Teknik Dergi, 311, ss.4759-4777.

Ömürbek, N., Öksüz Demirgubuz, M., Tunca, M. Z. (2015). Hizmet sektöründe performans ölçümünde veri zarflama analizinin kullanımı: havalimanları üzerine bir uygulama. Süleyman Demirel Üniversitesi Vizyoner Dergisi, 4(9), ss.21-43.

Özekes, S. (2003). Veri madenciliği modelleri ve uygulama alanları. İstanbul Ticaret Üniversitesi Dergisi, 2(3), ss.65-82.

Pekin, M. A., Kahraman, O., Coşkun, M. (2017). K-ortalamalar yöntemi ile sıcaklık ve yağış bakımından Türkiye'deki homojen bölgelerin belirlenmesi. IV. Türkiye İklim Değişikliği Kongresi, TiKDEK'2017, İstanbul, ss. 1-9

Pınar, M., Okumuş, O., Turgut, U. O., Kalıpsız, O., Aktaş, M. S. (2017). Büyük veri içeren öneri sistemleri için hiperparametre optimizasyonu. Ulusal Yazılım Mühendisliği Sempozyumu, ss. 22-272.

Sarıman, G. (2011). Veri madenciliğinde kümeleme teknikleri üzerine bir çalışma: k-means ve k-medoids kümeleme algoritmalarının karşılaştırılması. Süleyman Demirel Üniversitesi, Fen Bilimleri Enstitüsü Dergisi, 15(3), ss.192-202.

Sarkis, J., Talluri, S. (2004). Performance based clustering for benchmarking of US airports. Transportation Research Part A, 38, ss.329-346.

Savaş, S., Topaloğlu, N., Yılmaz, M. (2012). Veri madenciliği ve Türkiye'deki uygulama örnekleri. İstanbul Ticaret Üniversitesi Fen Bilimleri Dergisi, 11(21), ss.1-23

Suzuki, Y. (2007). Modeling and testing the "two-step" decision process of travelers in airport and airline choices. Transportation Research Part E 43, ss.1-20.

Tanyaş, M., Düzgün, M. (2015). İstanbul üçüncü havalimanı (IGA)'nın Türkiye için önemi ve geniş çaplı bölgesel hava trafiği üzerindeki etkisi. Loder Dergisi, 33, ss.37-45.

Tanyaş, M., (2014). İstanbul lojistik sektör analizi raporu. Müstakil Sanayici ve İşadamları Derneği Loder Dergisi.

Taşdelen, A. (2014). Veri madenciliği yöntemleri ile mühendislik fakültesi uzaktan eğitim bölümlerinin analizi: Karabük Üniversitesi. Yüksek Lisans Tezi, Karabük. 
Tekin B. (2015). Temel sağlık göstergeleri açısından Türkiye'deki illerin gruplandırılması: bir kümeleme analizi uygulaması. Çankırı Karatekin Üniversitesi, İktisadi ve İdari Bilimler Fakültesi Dergisi, 5(2), ss. 389-416.

URL-1, DHMi, (2017). 2017 aralık sonu (kesin olmayan) veriler. http://www.dhmi.gov.tr/istatistik.aspx 19 Temmuz 2018 tar

URL-2 UHDB, (2017). http://www.udhb.gov.tr/images/butce/6c72b7bc5767c2a.pdf. 19 Temmuz 2018 tarihinde erişildi.

URL-3, İpekci, E. (2016). Havayolu taşımacılığı, http://www.emreipekci.com/havayolu-tasimaciligi-html/ 19 Temmuz 2018 tarihinde erişildi.

Uysal, F. U., Ersöz, T., Ersöz, F. (2017). Türkiye'deki illerin yaşam endeksinin çok değişkenli istatistik yöntemlerle incelenmesi. Temel Bilimler Dergisi, 9(1), Türk Eğitim Bilimleri Dergisi, ss.49-65.

Wang, G., Cai, L., Shao, B., Chong, X., Hao, W., Xu, F. (2009). Comprehensive evaluation model of grey fixed weight clustering for airport pavement service performance. In International Conference on Transportation Engineering, ss. 984-989.

Wang, L., Taylor, C., Wanke, C. (2011). An airport clustering method for air traffic flow contingency management. In 11th AIAA Aviation Technology, Integration, and Operations (ATIO) Conference s. 6862

Wang, F., Xu, X. H. (2011). Mixed clustering algorithm of airport capacity in stochastic GHP model. Journal of Traffic and Transportation Engineering,1 (1), ss 1-12.

Wu, G., Xia, H.-S., Gao, Q. (2013). Optimization model of flight time and frequency under operation mode of multi-airports system. Jiaotong Yunshu Gongcheng Xuebao/Journal of Traffic and Transportation Engineering, 13(4), ss. 79-86.

Xia, L., Wang, J., Zhang, X., Wang, L. (2014). Application of cluster regression in time series prediction of airport noise. Shuju Caiji Yu Chuli/Journal of Data Acquisition and Processing, 29(1), ss. 152-156.

Yürük, F., Erdoğmuş, P. (2015). Düzce ilinin hayvansal atıklardan üretilebilecek biyogaz potansiyeli ve k-means kümeleme ile optimum tesis konumunun belirlenmesi. İleri Teknoloji Bilimleri Dergisi, 4(1), ss.47-56.

Zhu, B., Wu, G., Gao, Q. (2014). Optimization on flight frequencies and timetable in a multiple-airport system under hub congestion. Journal of Computational Information Systems,10(6), ss. 2587-2596. 